University of Nebraska - Lincoln

DigitalCommons@University of Nebraska - Lincoln

\title{
Selenium toxicity: cause and effects in aquatic birds
}

Julian E. Spallholz

Texas Tech University, jspallholz@hs.ttu.edu

David J. Hoffman

USGS Patuxent Wildlife Research Center, dhoffman@USGS.gov

Follow this and additional works at: https://digitalcommons.unl.edu/usgsstaffpub

Spallholz, Julian E. and Hoffman, David J., "Selenium toxicity: cause and effects in aquatic birds" (2002). USGS Staff -- Published Research. 574.

https://digitalcommons.unl.edu/usgsstaffpub/574

This Article is brought to you for free and open access by the US Geological Survey at DigitalCommons@University of Nebraska - Lincoln. It has been accepted for inclusion in USGS Staff -- Published Research by an authorized administrator of DigitalCommons@University of Nebraska - Lincoln. 


\title{
Selenium toxicity: cause and effects in aquatic birds
}

\author{
Julian E. Spallholz ${ }^{\mathrm{a}, *}$, David J. Hoffman ${ }^{\mathrm{b}}$

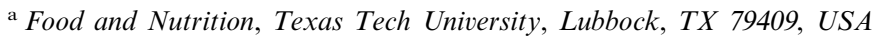 \\ ${ }^{\text {b } U S G S ~ P a t u x e n t ~ W i l d l i f e ~ R e s e a r c h ~ C e n t e r, ~ L a u r e l, ~ M D ~ 20708-4041, ~ U S A ~}$
}

\begin{abstract}
There are several manners in which selenium may express its toxicity: (1) an important mechanism appears to involve the formation of $\mathrm{CH}_{3} \mathrm{Se}^{-}$which either enters a redox cycle and generates superoxide and oxidative stress, or forms free radicals that bind to and inhibit important enzymes and proteins. (2) Excess selenium as selenocysteine results in inhibition of selenium methylation metabolism. As a consequence, concentrations of hydrogen selenide, an intermediate metabolite, accumulate in animals and are hepatotoxic, possibly causing other selenium-related adverse effects. (3) It is also possible that the presence of excess selenium analogs of sulfur-containing enzymes and structural proteins play a role in avian teratogenesis. L-selenomethionine is the most likely major dietary form of selenium encountered by aquatic birds, with lesser amounts of L-selenocysteine ingested from aquatic animal foods. The literature is suggestive that L-selenomethionine is not any more toxic to adult birds than other animals. L-Selenomethionine accumulates in tissue protein of adult birds and in the protein of egg white as would be expected to occur in animals. There is no suggestion from the literature that the levels of L-selenomethionine that would be expected to accumulate in eggs in the absence of environmental concentration of selenium pose harm to the developing embryo. For several species of aquatic birds, levels of Se as selenomethionine in the egg above $3 \mathrm{ppm}$ on a wet weight basis result in reduced hatchability and deformed embryos. The toxicity of L-selenomethionine injected directly into eggs is greater than that found from the entry of L-selenomethionine into the egg from the normal adult diet. This suggests that there is unusual if not abnormal metabolism of L-selenomethionine in the embryo not seen when L-selenomethionine is present in egg white protein where it likely serves as a source of selenium for glutathione peroxidase synthesis in the developing aquatic chick. (C) 2002 Elsevier Science B.V. All rights reserved.
\end{abstract}

Keywords: Selenium toxicity; Aquatic birds; Selenomethionine; Kesterson

\section{Introduction to selenium}

There are two distinct sides to the biological story of selenium (Se) that emerged from research

\footnotetext{
* Corresponding author. Tel.: + 1-806-742-3068; fax: + 1806-742-3042.

E-mail address: jspallholz@hs.ttu.edu (J.E. Spallholz).
}

in the later two-thirds of the 20th century. The first was the recognition of Se as an environmental toxicant of livestock in the western United States during the 1930s (Trelease and Beath, 1949), a theme that was to be replayed again in the central San Joaquin Valley of California in the 1980s. Only this time the toxicity of Se was found to affect primarily aquatic birds (Ohlendorf et al., 1988; Ohlendorf, 1989). 
The other significant biological aspect of Se to be recognized and emerge in the second half of the 20th century from research was the finding that selenium is a nutritionally essential trace nutrient. The complete story of the unfolding of events that led to the discovery of selenium as an essential nutrient is not the focus of this review but is of sufficient importance that a brief summary is given. German born physician Klaus Schwarz then working at the National Institutes of Health (NIH) at Bethesda, MD discovered that small amounts of selenium added to the diets of torula yeast fed rats consuming a diet low in Vitamin E prevented the occurrence of a condition know as dietary liver necrosis (Schwarz and Foltz, 1957). The year was 1957 and it culminated years of research by Dr Schwarz both in Germany and then after WW II at the NIH. This discovery subsequently led to the recognition that Se deficiency was the cause of numerous animal diseases throughout the world. The role of selenium in the prevention of these numerous dietary deficiency diseases was to be discovered at the University of Wisconsin. In 1973 John Rotruck, a graduate student at the time, observed differences in the oxidation of hemoglobin in the erythrocytes of rats fed either a selenium deficient diet or selenium adequate diet (Rotruck et al., 1973). The cause of the observed changes in the color of the hemoglobin contained within the erythrocytes was due to the absence of an erythrocyte enzyme, glutathione peroxidase. Glutathione peroxidase, an enzyme discovered by Mills in 1957, somewhat ironically in the same year of the report by Schwarz on dietary liver necrosis, contained selenium (Mills, 1957). Within a very short period of time Leopold Flohe (Flohe et al., 1973) in Germany, who had devoted his life to the study of glutathione peroxidase, heard the news that selenium might be contained in the enzyme. Reported in Science in 1973 that indeed, glutathione peroxidase contained $4 \mathrm{~g}$ /atoms of Se/mole of enzyme, Flohe was later heard to say that, "I could not believe that my beloved enzyme contained that awful poison selenium". In the years that followed other selenium containing enzymes were identified in bacterial systems, i.e. formate dehydrogenase, along with an ever growing family of glutathione peroxidases from insects, birds and ubiquitously from mammalian species. All of the classic glutathione peroxidases contained selenium and it was found to be involved in the catalytic reaction of these many enzymes (Allan et al., 1999). The major function of the glutathione peroxidases was found to involve the reduction of hydrogen peroxide to water at the expense of the oxidation of glutathione, the enzyme's cofactor. In 1984 a new glutathione peroxidase enzyme was discovered by Fulvio Ursini of the University of Padua, Italy. Isolated from pig liver this glutathione peroxidase was a membrane bound enzyme that contained selenium and was named phospholipidhydroperoxide glutathione peroxidase (Ursini et al., 1982). It differed from the classical glutathione peroxidase in that it had not been isolated from the cytoplasm and that it needed to be solublized from the membrane. The enzyme's spectrum of substrates was quite different from the cytosolic enzymes. Hydrogen peroxide was not a substrate for this new selenium peroxidase; rather the substrates were phospholipidhydroperoxides, as suggested by its name, as well as hydroperoxides of cholesterol. This enzyme for the first time revealed the long sought connection between selenium and Vitamin $\mathrm{E}$ and the prevention of dietary liver necrosis. This is how it came to be recognized that very small amounts of dietary selenium could spare the dietary requirement for the lipid bound antioxidant, Vitamin E (Ursini et al., 1985).

The following years revealed more selenium enzymes to be present in tissues including a new functional enzyme isolated from thyroid tissue, 5 -deiodinase, responsible for the conversion of tetraiodothyronine to triiodothyronine, the active thyroid hormone (Behne and Kyriakopoulos, 1990). More recently, thyrodoxin reductase, an enzyme responsible for regulation of the redox environment of cells was found to be a selenoenzyme (Lee et al., 2000). Research also led to the identification of selenocysteine as the common form of selenium in all presently identified selenoenzymes. In 1991 selenocysteine was designated the 21 st amino acid commonly found in proteins of many eubacetria, archaebacteria, prokayotes and of course euokaryotic cells of higher phylo- 
genic organisms (Bock et al., 1991). Molecular biology has remarkably revealed how selenium is incorporated into proteins via modification of a seryl-tRNA forming a selenocysteineyl-tRNA and incorporation into protein through a mRNA UGA codon. Previously believed to be a stop codon in mRNA, UGA is now universally recognized as the codon for selenocysteine. As will be discussed in the description of selenium toxicity, the chemical oxidation state of selenium suspected as toxic is the same chemical form of selenium contained in the selenium enzymes as selenocysteine, the selenide oxidation state, -2 , the selenoate anion.

\section{A brief history of selenosis}

More than 600 years ago Marco Polo, after returning to Venice from China, described to Marsden what is believed to be the first written description of selenium toxicity, i.e. selenosis. As recorded by Marsden, Polo was traveling the Silk Road in what is now Shanxi Province of Western China and learned about a poisonous plant that grew in the mountainous area. He learned that if any 'beast of burden ate the plants growing there it would cause their hoofs to drop off' and 'those people that traversed the area were aware of its dangerous qualities and took care to avoid it' (Marsden, 1962). The toxicity symptoms described by Marco Polo are those of selenosis in horses caused by the consumption of primary selenium accumulator plants, namely of the genus Astragalus. Astragalus is known to grow in seleniferous soils, often shales, in Western China as well as in the western US. It is common to the Dakotas, Colorado, Wyoming, Montana, New Mexico and Nebraska. Plants of this genus also extend up into Canada and occupy other scattered regions of the western and southwestern US. Other plant species, Xylorrhiza, Oonopsis and Stanleya are primary accumulators of soil selenium and have accounted for significant losses of livestock. Other plants, secondary accumulators of selenium, Astor, Atripex and Grindelia grow in seleniferous areas. Selenosis in cattle and sheep is referred to as blind staggers or alkali disease from the consumption of these seleniferous plants when other vegetation is usually sparse. Selenium is usually and better concentrated by these plants as selenates with lesser amounts of selenium concentrated as selenites. These plants convert inorganic selenium from soils to organic forms of selenium. Organic forms of selenium found in these plants include, dimethylselenide which is evolved as a gas, and non-protein amino acids, Se-methylselenocysteine, selenocystathionine, selenocysteine and selenohomocysteine. Non-selenium accumulator plants, i.e. cereal crops will volatize selenium if soil concentrations of selenium are high but when they are low or within the normal soil concentrations these 'food' crops predominantly synthesize the protein amino acid, L-selenomethionine. L-selenomethionine will replace the essential sulfur amino acid found in protein, methionine. The discovery and recognition of selenium as the cause of alkali disease and blind staggers occurred in the 1930s with the research being spearheaded primarily by the US Bureau of Chemistry and Soils at the South Dakota Agricultural Experiment Station (Muth et al., 1967). Much of the early work on the metabolism of selenium was done at the University of Wyoming, the Kaiser Foundation Research Institute, and Colorado State University.

For selenium to become toxic there must be some form of natural bioconcentration as occurs in both primary and secondary plant accumulators of selenium. The concentrations in some of these plants have been reported to reach several thousand $\mu \mathrm{g} \mathrm{Se} / \mathrm{g}$ of plant material. Another natural concentration of selenium is known to have occurred in coal in China. This natural concentration of selenium of up to $8 \%$ by weight has led to selenosis in humans in Hubei Province. This is the only place in the world where selenium toxicity in humans is known to occur naturally. Scattered throughout the world are other areas where selenosis is known to occur in animals but no place other than China is known for human selenium toxicity.

Selenium bioacummulation and subsequent selenosis primarily in aquatic birds have happened more recently in the central San Juaquin Valley of California. The San Juaquin Valley of California 
is one of the great agricultural areas of the world producing an abundance of fruits and vegetables, grains, nuts and fiber. In this semiarid valley a central drainage canal, the San Luis Drain was begun in 1968, for irrigation runoff and was intended when completed to empty into the Sacramento-San Joaquin River delta. Construction on the drainage project was halted in 1975 and remains uncompleted. The San Luis Drain terminated in Merced County in several ponds constituting the Kesterson Reservoir. Here runoff of irrigation and natural precipitation collected, and dissolved solutes became concentrated due to evaporation. Selenium found concentrated in some of the exposed shales of the Central Valley and originating in the Panoche Hills area on the southwestern edge of the valley found its way to the Kesterson Reservoir (Ohlendorf et al., 1988; Ohlendorf, 1989). During 1987 one of us, (JES) visited the drainage ponds of the Kesterson Reservoir for a personal look at the consequence of reports of selenium toxicity in birds inhabiting the area. Unlike other ponds that I had observed in my youth these ponds looked biologically dead with no signs of vegetative or animal life. The water in these ponds appeared to be pristine because of its clarity. That these ponds had high concentrations of mineral salts was evident from the growth of mineralized crystals in the water. Birds were flying all around the area with stilts, coots, grebes, avocets and ducks, including mallards, gadwalls, cinnamon teals and northern pintails reported to be frequent visitors to Kesterson Reservoir. Selenium toxicity had been reported to be a cause of death and deformities of embryos and chicks within the Kesterson area. Here in the Kesterson area selenosis was caused by high concentrations of selenium in the run off which had bioaccumulated in the bird's food chain by plants, invertebrates and fish (Ohlendorf et al., 1988).

\section{Why is selenium toxic}

It is hypothesized that heavy metal toxicity, mercury, lead, cadmium, silver and other potentially toxic metals such as iron and copper, along with the non-metals arsenic and selenium, all share in part at least one common interaction in biological systems that causes toxicity symptoms to occur, the generation of superoxide $\left(\mathrm{O}_{2}^{-}\right)$. (Stohs and Bagchi, 1995) This common cause of initiating toxicity symptoms, beyond differences in concentration and chemical form is due to their interaction with thiols in mammals (Klassen et al., 1985) and in birds (Hoffman and Heinz, 1998). Reaction with thiols could alter the activity of many different essential sulfhydryl-containing enzymes as well as structural proteins within an organism. However, in reacting with thiols these elements also appear to generate free radicals, initially superoxide and precipitate the generation there from other reactive oxygen species (Xu et al., 1991; Spallholz, 1994). Of the elements listed above, selenium is the most toxic to living systems depending upon chemical form ingested (Stewart et al., 1999). Selenium, classified as a non-metal has exquisite metallic properties that can undergo facile redox reactions with thiols. Herein lies the general explanation for selenium's toxicity. It is an oxidizing catalyst of the first order in the selenide $(-2)$ oxidation state able to continuously oxidize thiols such as glutathione (GSH) and reduce oxygen producing the free radical, superoxide $\left(\mathrm{O}_{2}^{-\bullet}\right)$ (Xu et al., 1991). The details of this reaction have been described in detail by Chaudiere et al. (1992) (Fig. 1) and the selenium compounds that undergo a redox cycle have been cataloged by Spallholz et al. $(1998,2001)$ (Table 1).

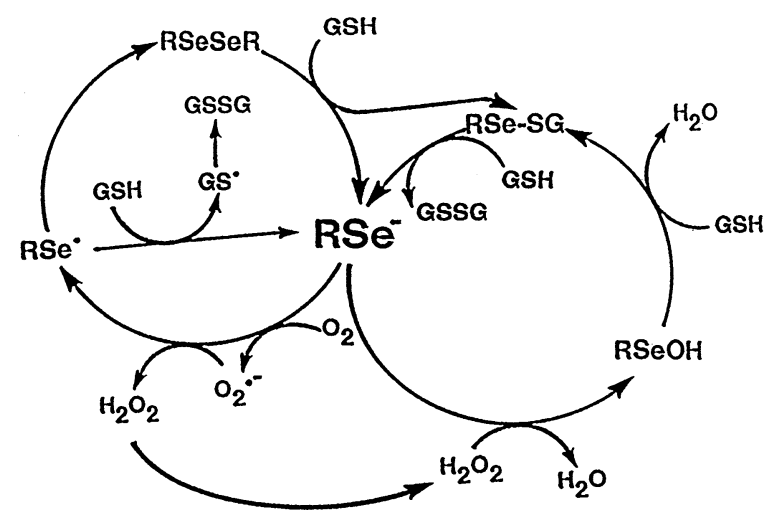

Fig. 1. Redox cycle of selenides ( R Se-) generating superoxide. From Chaudiere et al. (1992). 
Table 1

Selenium compounds that generate and do not generate superoxide in vitro

Superoxide generated in vitro Superoxide not generated in vitro

\section{Selenite}

Selenium dioxide

Selenocysteine

Selenocystamine

Diselenopropionic acid

Diphenyldiselenide

Dibenzyldiselenide

1,4-Phenylenebis(methylene)

selenocyanate $^{\mathrm{b}}$

6-Propylselenouricil ${ }^{\mathrm{c}}$

Dimethyldiselenide

Methylseleninic acid $^{\mathrm{a}}$ excess selenocysteine as a consequence of inhibition of selenium methylation metabolism (Sayato et al. 1997). Excess hydrogen selenide contributes to hepatotoxicity and could contribute to other selenium related injuries.

In animal toxicity trials (Oldfield, 1999) many selenium compounds have been tested both for their acute and chronic toxicity. During the 1970s following the discovery of selenium as a component of glutathione peroxidase, Schwarz spent much time and effort trying to find a selenium compound that was effective for supporting the synthesis of glutathione peroxidase in rats but that was not toxic. Until his death in 1978 none was found and no one else has taken up the lance. Sodium selenite and selenate while toxic above $4-5 \mu \mathrm{g} / \mathrm{g}$ of diet fully support glutathione peroxidase synthesis. So do the other more natural forms of selenium encountered by animals and humans alike in their normal course of consuming foods, L-selenomethionine and selenocysteine. Selenomethionine, unlike selenate and selenite is much less toxic to animals and humans. In rats, selenium as L-selenomethionine is tolerable without any toxicity symptoms up to about $40 \mu \mathrm{g} / \mathrm{Se}$ per $g$ of diet. There is, however, some aversion to these abnormally high Se containing diets beginning at $20 \mu \mathrm{g} / \mathrm{Se}$ per $\mathrm{g}$ of diet (Spallholz, unpublished). Thus the transition from dietary essential nutrient consumed naturally by animals from their environment is not so much limited by the chemical form of selenium but by amounts and subsequent metabolism. Selenium is dietary essential to nearly all living animals but not plants, and becomes toxic when excess is consumed. To paraphrase the 16th century physician, Paracelsus, who stated that "It is the dose that makes the poison"; it is the amount and chemical form of selenium consumed that make it toxic.

\section{Speciation of selenium compounds in plants}

Selenium is encountered in soils normally at low concentrations, $0.1-2.0 \mu \mathrm{g} / \mathrm{g}$ occasionally exceeded by $100 \mu \mathrm{g} / \mathrm{g}$ in some geological strata. Here we find inorganic forms of selenium, selenates $(+6)$ and selenites $(+4)$. Selenates predomand organic selenium compounds in animals. Hydrogen selenide accumulates in animals receiving 
inate in soils and are rapidly and more readily assimilated by plants. Selenates are found in drier alkaline soils. In acid soils, selenites react with and are converted to $\mathrm{Fe}^{+3}$-selenite complexes, which are less readily assimilated by plants. Elemental selenium $\left(\mathrm{Se}^{0}\right)$ in soils is nearly inert to plant assimilation (Lauchli, 1993). When assimilated by non-accumulator plants selenates and selenites are converted to organic forms of selenium. In general, non-accumulator Se plants, cereal crops and grains used for human food, and grasses convert most inorganic selenium into the protein amino acid, L-selenomethionine. Lesser amounts of other selenoamino acids may be present. Selenium accumulator plants make non-proteinecious amino acids such as L-Semethylselenocysteine, L-selenocystathionine, L-selenocysteine and L-selenohomocysteine. All plants exposed to selenium at concentrations that exceed normal biosynthetic pathway volatize dimethylselenide. Small animals including fish that consume these plants deposit L-selenomethionine in their proteins in place of methionine and from selenomethionine and some other trace amounts of selenite, selenate or selenoamino acids make L-selenocysteine found in glutathione peroxidase (Lemly and Smith, 1987; Presser and Ohlendorf, 1987; Ohlendorf, 1989).

\section{Selenium in the diets of aquatic birds}

With the exception of birds of prey most aquatic birds would most likely be exposed to selenium as L-selenomethionine, with perhaps lesser amounts of L-selenocysteine from ingested insects and fish. Ingestion of inorganic selenium, only as selenite or selenate, and in concentrations such as appear to have occurred at the Kesterson reservoir, would be expected to be very low and nutritionally insignificant. Thus it is somewhat serendipitous that many of the controlled Se toxicity trials with aquatic birds appear to have been conducted primarily with either L- or D,L-selenomethionine (Heinz, 1996). Studies in chickens have examined the toxicity of inorganic as well as organic selenium compounds (Latshaw and Osman, 1975). Selenite is the common supplement for chicks to prevent exudative diathesis and other selenium deficiency conditions (Osman and Latshaw, 1976), whereas aquatic birds almost never encounter significant amounts of selenite in the wild in the absence of pollution.

\section{Toxicity of selenium in aquatic birds}

Laboratory toxicity studies of selenium compounds administered in the diet of aquatic birds have been conducted primarily with mallards with focus on three stages of the life cycle: (1) most notably, reproductive studies on embryotoxic, teratogenic and other developmental effects as a consequence of feeding the parents graded concentrations of selenium, (2) feeding studies on duckling growth and survival, and (3) fewer studies in adults, examining histopathological effects. In many of these studies, selenomethionine (either $\mathrm{D}, \mathrm{L}$ or $\mathrm{L}$ ) was the form of Se selected since it was thought to be the most likely encountered dietary form of selenium in nature for birds feeding on grains, seeds and grasses. Aquatic birds feeding on a mixed diet of plant foods and small crustaceans and fish would ingest lesser amounts of selenium as L-selenocysteine.

\subsection{Reproductive effects}

In the first of several reproductive studies, mallards were fed a control diet, diets containing 1, 5, 10 , or $25 \mathrm{ppm} \mathrm{Se}$ as sodium selenite, or a diet containing $10 \mathrm{ppm}$ Se as D,L-selenomethionine. Se at $10 \mathrm{ppm}$ as selenomethionine or $25 \mathrm{ppm}$ as sodium selenite caused a $40-44 \%$ decrease in the total number of eggs that hatched compared with controls (Heinz et al., 1987; Hoffman and Heinz, 1988). About $10 \mathrm{ppm}$ Se as selenomethionine was more teratogenic than sodium selenite at $25 \mathrm{ppm}$. Selenomethionine (10 ppm Se) resulted in an incidence of $13.1 \%$ malformations that were often multiple, whereas sodium selenite $(10$ and $25 \mathrm{ppm}$ Se) resulted in 3.6 and $4.2 \%$ malformations. The teratogenicity of selenomethionine was confirmed in a second study in which mallards received 1, 2, 4, 8, or $16 \mathrm{ppm}$ Se as D,L-selenomethionine, resulting in $0.9,0.5,1.4,6.8$, and $67.9 \%$ malforma- 
tions, respectively (Heinz et al., 1989). In contrast $16 \mathrm{ppm}$ Se as selenocysteine did not impair reproduction. With Se as selenite or selenocysteine in the diet there was little accumulation in eggs compared with that for $\mathrm{Se}$ as selenomethionine. Comparison of L-selenomethionine, D,L-selenomethionine, and selenized yeast on reproduction showed the $\mathrm{L}$ and $\mathrm{D}, \mathrm{L}$ forms to be similar in toxicity, but selenized yeast to be less toxic and to accumulate somewhat less in eggs (Heinz et al, 1996). With Se as selenomethionine in mallards, egg concentrations of Se as well as frequency and types of malformations were similar to those reported to cause hatching failure and teratogenesis in wild aquatic birds. A laboratory study of limited sample size suggested that black-crowned night-herons may be less sensitive to reproductive effects of selenium than mallards (Smith et al., 1988).

\subsection{Duckling growth and survival}

When day-old ducklings were fed $0.1,10,20$, 40 , or $80 \mathrm{ppm}$ Se as sodium selenite or as D,L-selenomethionine for 6 weeks, both forms of $\mathrm{Se}$ impaired duckling growth at $20 \mathrm{ppm}$ and survival at $40 \mathrm{ppm}$, with effects of sodium selenite being somewhat greater (Heinz et al., 1988). Both forms resulted in virtually complete mortality at $80 \mathrm{ppm}$ Se. Se from selenomethionine accumulated in a dose-dependent manner in the liver whereas accumulation from Se as selenite was much less. Further studies with Se in ducklings at 15 and $60 \mathrm{ppm}$ in the diet confirmed the previous findings for selenomethionine (Hoffman et al., 1991b, 1992a,b). In these studies decreased growth occurred at $15 \mathrm{ppm} \mathrm{Se}$ in the diet, and decreased survival with histopathological lesions at $60 \mathrm{ppm}$ in the diet. More recent studies have suggested that L-selenomethionine may be somewhat more toxic to ducklings than D,L-selenomethionine under certain dietary conditions. For example, with a wheat based diet effects on survival and growth were greater with $30 \mathrm{ppm}$ Se as L-selenomethionine than D,L-selenomethionine or other Se groups that were studied, including selenized yeast and wheat (Heinz et al., 1996; Hoffman et al., 1996). In contrast, when a different and commercially- based basal diet was provided, survival of ducklings was not affected by $30 \mathrm{ppm}$ Se and growth impairment did not differ among Se treatment groups. Since most previous avian toxicity studies with selenomethionine were conducted with D,Lselenomethionine, that was commercially available, it is possible that the full potential toxicity of Se as naturally occurring L-selenomethionine may have been underestimated.

\subsection{Adult mallards}

Immune function was decreased by Se as selenomethionine $(2.2 \mathrm{mg} / \mathrm{l} \mathrm{Se}$ in drinking water) but not as selenite $(3.5 \mathrm{mg} / 1 \mathrm{Se}$ in drinking water) in adult mallards exposed for 12 weeks (Fairbrother and Fowles, 1990). Sodium selenitetreated birds did not display any Se accumulation in tissues above control levels. Serum ALT activity was increased by both treatments but to a lesser extent by selenite. In a mallard reproductive study with selenite, adult mallard mortality of 5\% and weight loss began at a dietary concentration of $25 \mathrm{ppm}$ Se and reached almost $100 \%$ at 100 ppm Se (Heinz et al., 1987).

When adult male mallards received a control diet $(0.2 \mathrm{ppm} \mathrm{Se})$ or diets containing 1, 2, 4, 8, 16, or $32 \mathrm{ppm} \mathrm{Se}$ as selenomethionine for 14 weeks, Se accumulated readily in the liver in a dose-dependent manner, reaching a mean concentration of $29 \mathrm{ppm}(\mathrm{ww})$ in the $32 \mathrm{ppm}$ group (Hoffman et al., 1991a). Mortality (10\%) and histopathological effects, including bile duct hyperplasia and hemosiderin pigmentation of the liver and spleen, occurred in the $32 \mathrm{ppm}$ group. Other studies developed diagnostic criteria for selenium toxicosis with DL-selenomethionine $(0,10,20,40$, or 80 ppm Se) in the diet of adult mallards for 16 weeks (Albers et al., 1996; Green and Albers, 1997). Mortality was 5, 14, and $100 \%$ in the 20,40 , and $80 \mathrm{ppm}$ groups, respectively. Ducks receiving 40 and $80 \mathrm{ppm}$ Se exhibited decreased body weight and histopathological lesions. Criteria for diagnosis of fatal selenosis in these two groups included consistent histologic lesions in the liver, kidneys, and organs of the immune system. At Kesterson Reservoir, mortality and histopathological lesions in adult American coots (Fulica americana) were 
related to selenium exposure, most likely as selenomethionine (Ohlendorf et al., 1988). The hepatic Se residues and lesions found in the coots were similar to those reported in the above mallard studies.

\section{Egg injection studies with selenium compounds}

The second most notable effects of selenium toxicity have been assessed on the fertile eggs of chickens or aquatic birds themselves whereby selenium is injected directly into the air cell of the egg. Titration of selenium concentrations into eggs has been done for a wider variety of selenium compounds than feeding studies, but again most research interest has again focused on L- or D,Lselenomethionine. A number of researchers have investigated the toxicity of selenium compounds directly on the chick embryo by injection of selenium directly into the air cell. The earliest studies of this kind date back to that of Franke and Painter (1937) who studied the toxicity of selenite. Similar studies were done by Halverson et al. (1965). The most interesting of these kinds of experiments were done by Palmer et al. (1973). They investigated the toxicity of eight different selenium compounds by direct injection of increasing concentrations of selenium into 4day-old embryos. These experiments revealed that the order of toxicity of selenium (ppm Se) to the embryos was: (LD50) methylseleninic acid, $0.052>$ selenate, $\quad 0.13=$ selenomethionine, $0.13>$ selenite, $\quad 0.30>$ Se-methylselenocysteine, $0.57>$ selenocysteine, $0.64>$ dimethylselenoxide, $6.53>$ trimethylselenonium chloride, 15.7 .

\section{Discussion}

Selenium toxicity in aquatic birds in the wild has been reported in a dozen or so environmental situations where selenium and other minerals from agricultural runoff and other sources have tended to accumulate due to evaporation of surface waters (Skorupa, 1998). However, the literature is not reflective of reports of widespread $\mathrm{Se}$ toxicity in birds from normal background levels of naturally occurring environmental selenium, or from bioaccumulation of selenium in the food chain where normal background levels of Se exist.

As has been reported for non-avian species of animals, mostly rats and mice, when birds receive diets supplemented with L-selenomethionine, selenium in this biochemical form appears to concentrate in a dose dependent manner primarily in muscle tissue and to a lessor extent in liver tissue (Wilson et al., 1997; Hoffman et al., 1991a). In eggs, L-selenomethionine has been shown to be concentrated in the egg white of chickens (Moksnes, 1983) and mallard ducks (Heinz, 1993). It is well known that L-selenomethionine will fully replace L-methionine in the primary structure of protein and will do so in a dose dependent manner. There is no reason to suspect those concentrations of L-selenomethionine from natural environmental settings and its concentration in muscle protein or egg white posses any toxicity threats to adult birds or their chicks. Only when environmentally concentrated forms of selenium occur or diets continually exceed $>$ ca. 15 ppm selenium would toxic manifestations arise. Diets fed to adult mallards containing $16 \mathrm{ppm}$ selenium as D,L-selenomethionine were not reported to cause histopathological lesions or mortality (Hoffman et al., 1991a).

Selenium in the diet as selenite was somewhat more toxic to mallard ducklings than selenium as selenomethionine with greater effects on growth at $20 \mathrm{ppm}$ and on survival at $40 \mathrm{ppm}$ (Heinz et al., 1988). Dietary concentrations of 15 or $20 \mathrm{ppm}$ selenium formulated with selenite appear to be even more toxic to growing chickens and adult chickens than to mallards. These effects in birds are similar in response that would be observed experimentally in mice or rats. The threshold for growth reduction in Cobb chicks was ca. 9 ppm selenium as selenite, whereas growth reduction was observed in broiler chicks at $5 \mathrm{ppm}$ selenium. The differences in toxicity between selenite and L-selenomethionine appear to be more pronounced in organ culture of fetal limb buds. Selenite induced a dose-related effect on mouse fetal limb bud growth whereas L-selenomethionine had no effect on the limb bud development at the same selenium concentrations (Rousseaux et al., 
1992). However, when fed to ducklings, if selenite and selenomethionine are compared on a similar basis the resulting liver concentrations of selenium, are much lower resulting from selenite than selenomethionine and are associated with similar or greater toxic effects including hepatic oxidative stress, impaired growth and survival (Hoffman et al., 1989), suggesting a greater toxicity of selenite than selenomethionine once present in the tissue of ducklings or adults.

Egg injection studies revealed that the order of toxicity of selenium compounds was methylseleninic acid $>$ selenate $=$ selenomethionine $>$ selenite $>$ Se-methylselenocysteine $>$ selenocysteine $>$ dimethylselenoxide $>$ trimethylselenonium chloride. What is particularly interesting in this series of selenium compounds is that the order of increasing selenium toxicity is not what would be expected if the study was done on animal cells in culture. And yet there are similarities in toxicity of what would be the predicted order of selenium toxicity. That order in view of the present understanding of selenium as a dose dependent generator of superoxide and oxidative stress would be; methylseleninic acid, selenite, selenate, selenocystine, Se-methylselenocysteine, selenomethionine, dimethylselenoxide and trimethylselenium chloride. Methylseleninic acid and selenite are highly active as redox catalysts, selenate becomes catalytic upon reduction to selenite, selenocystine becomes catalytic upon reduction to selenocysteine, Se-methylselenocysteine and selenomethionine become toxic and catalytic upon metabolism by what is believed to be B-lyases (Andreadou et al., 1996; Ip et al., 2000). Dimethyselenoxide and the trimethylselenionium ion are not catalytic in in vitro assays nor are they very toxic to animals in vivo. Thus, the interesting finding is that selenomethione appears to be extremely toxic and teratogenic to avian embryos, but based upon other published studies does not appear to be any more toxic in adult birds than in other non-avian animals. This would seem to be possible only if there were enzymes present in the egg that effectively metabolized the B-elimination of methylselenol from selenomethionine which is equivalent to methylseleninic acid, i.e. both compounds produce $\mathrm{CH}_{3} \mathrm{Se}^{-}$, and there must be no mechanism for methylation and detoxification in the egg which normally occurs in liver and other tissues of the adult bird.

\section{Conclusions}

There are several ways in which selenium may express its toxicity. One important mechanism involves the formation of $\mathrm{CH}_{3} \mathrm{Se}^{-}$, which either enters a redox cycle and generates superoxide and oxidative stress, or forms free radicals that bind to and inhibit important enzymes and proteins. It is also possible that the presence of excess selenium analogs of sulfur-containing enzymes and structural proteins may play a role in avian teratogenesis associated with excess selenium in the diet. Hepatotoxic concentrations of hydrogen selenide accumulate in animals receiving excess selenocysteine when there is inhibition of selenium methylation metabolism. Accumulation of hydrogen selenide could cause other selenium-related adverse effects. However, L-selenomethionine is the most likely major dietary form of selenium encountered by aquatic birds, with lesser amounts of L-selenocysteine ingested from aquatic animal foods. L-selenomethionine is not any more toxic to adult birds than other animals. L-Selenomethionine readily accumulates in tissue proteins of adult birds and in the protein of egg white. However, there is no suggestion from the literature that the levels of L-selenomethionine that would be expected to accumulate in eggs in the absence of environmental concentration of selenium pose harm to the developing embryo. For several species of aquatic birds, levels of $\mathrm{Se}$ as selenomethionine in the egg above $3 \mathrm{ppm}$ on a wet weight basis result in reduced hatchability and deformed embryos. The toxicity of L-selenomethionine injected directly into eggs is greater than that found from the entry of L-selenomethionine into the egg from the normal adult diet. This suggests that there is unusual if not abnormal metabolism of L-selenomethionine in the embryo not seen when L-selenomethionine is present in egg white protein where it likely serves as a source of selenium for glutathione peroxidase synthesis in the developing aquatic chick. 


\section{References}

Allan, C.B., Lacouriciere, G.M., Stadtman, T.C., 1999. Responsiveness of selenoproteins to dietary selenium. Annu. Rev. Nutr. 19, 1-16.

Albers, P.H., Green, D.E., Sanderson, C.J., 1996. Diagnostic criteria for selenium toxicosis in aquatic birds: dietary exposure, tissue concentrations, and macroscopic effects. J. Wildlife Diseases 32, 468-485.

Andreadou, I., Wiro, B.M., Commandeur, J.N.M., Worthington, E.A., Vermeulen, N.P.E., 1996. Synthesis of novel Se-substituted selenocysteine derivatives as potential kidney selective prodrugs of biologically active selenol compounds: evaluation of kinetics of $\beta$-elimination reactions in rat renal cytosol. J. Med. Chem. 39, 2040-2046.

Behne, D., Kyriakopoulos, A., 1990. Identification of type I iodothyronine $5^{\prime}$-deiodinase as a selenoenzyme. Biochem. Biophys. Res. Commun. 173, 1143-1149.

Bock, A., Forchhammer, K., Heider, J., Leinfelder, W., Sawers, G., Veprek, B., Zinoni, F., 1991. Selenocysteine: the 21st amino acid. Mol. Microbiol. 5, 515-520.

Chaudiere, J., Courtin, O., Leclaire, J., 1992. Glutathione oxidase activity of selenocystamine: a mechanistic study. Arch. Biochem. Biophys. 296, 328-336.

Daniels, L.A., 1996. Selenium metabolism and bioavailability. Biol. Trace Elem. Res. 54, 185-199.

Fairbrother, A., Fowles, J., 1990. Subchronic effects of sodium selenite and selenomethionine on several immune functions in mallards. Arch. Environ. Contam. Toxicol. 19, 836-844.

Flohe, L., Gunzler, W.A., Schock, H.H., 1973. Glutathione peroxidase: a selenoenzyme. FEBS Lett. 32, 132-138.

Franke, K.W., Painter, E.P., 1937. Effect of sulfur additions on seleniferous soils. Binding of selenium by soil. Ind. Eng. Chem. 29, 591-595.

Green, D.E., Albers, P.H., 1997. Diagnostic criteria for selenium toxicosis in aquatic birds: histologic lesions. J. Wildlife Diseases 33, 385-404.

Halverson, A.W., Jerde, L.G., Hills, C.L., 1965. Toxicity of inorganic selenium salts to chick embryos. Toxicol. Appl. Pharm. 7, 675-679.

Heinz, G.H., 1993. Selenium accumulation and loss in mallard eggs. Environ. Toxicol. Chem. 12, 775-778.

Heinz, G.H., 1996. Selenium in birds. In: Environmental Contaminants in Wildlife; Interpreting Tissue Concentrations. CRC Press, Boca Raton, FL, pp. 445-456 Chapter 20.

Heinz, G.H., Hoffman, D.J., Krynitsky, A.J., Weller, D.M.G., 1987. Reproduction in mallards fed selenium. Environ. Toxicol. Chem. 6, 423-433.

Heinz, G.H., Hoffman, D.J., Gold, L.G., 1988. Toxicity of organic and inorganic selenium to mallard ducklings. Environ. Toxicol. Chem. 17, 561-568.

Heinz, G.H., Hoffman, D.J., Gold, L.G., 1989. Impaired reproduction of mallards fed an organic form of selenium. J. Wildlife Manage. 53, 418-428.

Heinz, G.H., Hoffman, D.J., LeCaptain, L.J., 1996. Toxicity of L-selenomethionine, D, L-selenomethionine, high selenium wheat, and selenized yeast to mallard ducklings. Arch. Environ. Contam. Toxicol. 30, 93-99.
Hoffman, D.J., Heinz, G.H., 1988. Embryotoxic and teratogenic effects of selenium in the diet of mallards. J. Toxicol. Environ. Health 24, 477-490.

Hoffman, D.J., Heinz, G.H., 1998. Effects of mercury and selenium on glutathione metabolism and oxidative stress in mallard ducks. Environ. Toxicol. Chem. 17 (2), 161-166.

Hoffman, D.J., Heinz, G.H., Krynitsky, A.J., 1989. Hepatic glutathione metabolism and lipid peroxidation in response to excess dietary selenomethionine and selenite in mallard ducklings. J. Toxicol. Environ. Health 27, 263-271.

Hoffman, D.J., Heinz, G.H., LeCaptain, L.J., Bunck, C.M., Green, D.E., 1991a. Subchronic hepatoxicity of selenomethionine in mallard ducks. J. Toxicol. Environ. Health 32, 449-464.

Hoffman, D.J., Sanderson, D.J., LeCaptain, L.J., Cromartie, E., Pendleton, G.S., 1991b. Interactive effects of boron, selenium and dietary protein on survival, growth, and physiology in mallard ducklings. Arch. Environ. Contam. Toxicol. 20, 49-464.

Hoffman, D.J., Sanderson, D.J., LeCaptain, L.J., Cromartie, E., Pendleton, G.S., 1992a. Interactive effects of arsenic, selenium, and dietary protein on survival, growth, and physiology in mallard ducklings. Arch. Environ. Contam. Toxicol. 20, 288-294.

Hoffman, D.J., Sanderson, D.J., LeCaptain, L.J., Cromartie, E., Pendleton, G.W., 1992b. Interactive effects of selenium methionine and dietary protein on survival, growth, and physiology in mallard ducklings. Arch. Environ. Contam. Toxicol. 23, 163-186.

Hoffman, D.J., Heinz, G.H., LeCaptain, L.J., Eisemann, J.D., Pendleton, G.W., 1996. Toxicity and oxidative stress of different forms of organic selenium and dietary protein in mallard ducklings. Arch. Environ. Contam. Toxicol. 31, $120-127$.

Ip, C., Thompson, H.J., Zhu, Z., Ganther, H.E., 2000. In vitro and in vivo studies of methylseleninic acid: evidence that a monomethylated selenium metabolite is critical for cancer chemoprevention. Cancer Research, 11:2882-2886.

Klassen, C.D., Bracken, W.M., Dudley, R.E., Goering, P.L., Hazelton, G.A., Hjelle, J.D., 1985. Role of sulfhydryls in the hepatotoxicity of organic and metallic compounds. Fundam. Appl. Toxicol. 5, 806-815.

Latshaw, J.D., Osman, M., 1975. Distribution of selenium in egg white and yolk after feeding natural and synthetic selenium compounds. Poultry Sco. 54, 1244-1252.

Lauchli, A., 1993. Selenium in plants: uptake, functions and environmental toxicity. Bot. Acta 106, 455-468.

Lee, S.R., Bar-Noy, S., Kwon, J., Levine, R.L., Stadtman, T.C., Rhee, S.G., 2000. Mammalian thioredoxin reductase: oxidation of the C-terminal cysteine/selenocysteine active site forms a thioselenide and replacement of selenium with sulfur markedly reduces catalytic activity. Proc. Natl. Acad. Sci. 97, 2521-2526.

Lemly, A.D., Smith, G.J., 1987. Aquatic cycling of selenium: implications for fish and wildlife. United States Dept. Inter./Fish and Wildlife Service Leaflet No. 12, 1-10. 
Marsden, 1962. The Travels of Marco Polo. The Heritage Press, Norwich, CT.

Mills, G.C., 1957. Hemoglobin catabolism I. Glutathione peroxidase, an erythrocyte enzyme which protects hemoglobin from oxidative breakdown. J. Biol. Chem. 229, 589-598.

Moksnes, K., 1983. Selenium deposition in tissues and eggs of laying hens given surplus of selenium as selenomethionine. Acta Vet. Scand. 24, 34-44.

Muth, O.H., Oldfield, J.E., Weswig, P.H., 1967. Selenium in Biomedicine. AVI Publishing Co., Inc, Westport, CT.

Ohlendorf, H.M., 1989. Bioaccumulation and effects of selenium in wildlife. Soil Sci. Soc. Am., Am. Soc. Agron. 23, $133-177$.

Ohlendorf, H.M., Kilness, A.W., Simmons, J.L., Stroud, R.K., Hoffman, D.J., Moore, J.F., 1988. Selenium toxicosis in wild aquatic birds. J. Toxicol. Environ. Health 24, 67-92.

Oldfield, J.E., 1999. Selenium World Atlas. Selenium Tellurium Development Association (STDA), Brussels, Belgium.

Osman, M., Latshaw, J.D., 1976. Biological potency of selenium from sodium selenite, selenomethionine, and selenocysteine in the chick. Poultry Sci. 55, 987-994.

Palmer, I.S., Arnold, R.L., Carlson, C.W., 1973. Toxicity of various selenium derivatives to chick embryos. Poultry Sci. 52, $1841-1846$.

Presser, T.S., Ohlendorf, H.M., 1987. Biogeochemical cycling of selenium in the San Joaquin Valley, California, USA. Environ. Manage. 11, 805-821.

Rotruck, J.T., et al., 1973. Selenium: biochemical role as a component of glutathione peroxidase. Science 179, 588590.

Rousseaux, C.G., Politis, M.J., Keiner, J., 1992. The effects of sodium selenite and selenomethionine on murine limb development in culture. Environ. Toxicol. Chem. 12, 12831290.

Sayato, Y., Nakamuro, K., Hasegawa, T., 1997. Selenium methylation and toxicity mechanism of selenocysteine. Yakugaku Zasshi 117, 665-672.

Schwarz, K., Foltz, C.M., 1957. Selenium as an integral part of factor 3 against necrotic liver degeneration. J. Am. Chem. Soc. 79, 3292-3293.

Skorupa, J.P., 1998. Selenium poisoning of fish and wildlife in nature: lessons from twelve real-world examples. In:
Frankenburger, W.T. Jr, Engberg, R.A. (Eds.), Environmental Chemistry of Selenium. Marcel Dekker, New York, NY, pp. 315-354.

Smith, G.J., Heinz, G.H., Hoffman, D.J., Spann, J.W., Krynitsky, A.J., 1988. Reproduction in black-crowned night-herons fed selenium. Lake Resevior Manage. 4, 175180 .

Spallholz, J.E., 1994. On the nature of selenium toxicity and carcinostatic activity. Free Radic. Biol. Med. 17, 45-64.

Spallholz, J.E., Reid, T., Boylan, L.M., Shriver, B., 1998. Selenium Free Radical Chemistry: Applications for Pharmaceuticals. Proceedings of the 6th International Symposium on Selenium and Tellurium. (STDA) 47-56. Scottsdale, AZ.

Spallholz, J.E., Shriver, Brent J., Reid, Ted W., 2001. Dimethyldiselenide and Methylseleninic acid generate superoxide in an in vitro chemiluminescence assay in the presence of glutathione: implications for the anticarcinogenic activity of L-selenomethionine and L-Se methyselenocysteine. Nutrition and Cancer 40, 34-41.

Stewart, M., Neldner, K., Spallholz, J., Pence, B., 1999. Selenite, selenocystamine, and selenomethionine have disparate abilities to impose oxidative stress and induce apoptosis in mouse keratinocytes. Free Radic. Biol. Med. 26, 42-48.

Stohs, S.J., Bagchi, D., 1995. Oxidative mechanisms in the toxicity of metal ions. Free Radic. Biol. Med. 18, 321-336.

Trelease, F., Beath, O.A., 1949. Selenium. Champlain Printers, Burlington, VT.

Ursini, F., Maiorino, M., Valente, M., Ferri, L., Gregolin, C., 1982. Purification from pig liver of a protein which protects liposomes and biomembranes from peroxidative degradation and exhibits glutathione peroxidase activity on phosphatidylcholine hydroperoxides. Biochim. Biophys. Acta 710, 197-211.

Ursini, F., Maiorino, M., Gregolin, C., 1985. The selenoenzyme phospholipid hydroperoxide glutathione peroxidase. Biochim. Biophys. Acta 839, 62-70.

Wilson, D.S., Zhang, P., He, R., Ota, R., Omaye, S.T., 1997. Kinetics of selenium incorporation into tissues of female mallard ducks. Toxicology 122, 51-60.

Xu, H., Feng, Z., Yi, C., 1991. Free radical mechanism of the toxicity of selenium compounds. Huzahong Longong Daxue Xuebao 19, 13-19. 